\title{
A Pilot Study of Eptifibatide for Treatment of Acute Pain Episodes in Sickle Cell Disease
}

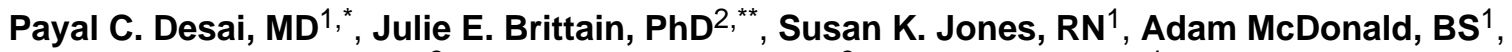 \\ Douglas R. Wilson, BSPH ${ }^{3}$, Rosalie Dominik, $\mathrm{DrPH}^{3}$, Nigel S. Key, MD ${ }^{1}$, Leslie V. Parise, \\ PhD $^{2}$, and Kenneth I. Ataga, MBBS ${ }^{1}$ \\ ${ }^{1}$ Division of Hematology/Oncology, University of North Carolina, Chapel Hill \\ ${ }^{2}$ Department of Biochemistry and Biophysics, University of North Carolina, Chapel Hill \\ ${ }^{3}$ Department of Biostatistics, University of North Carolina, Chapel Hill
}

\begin{abstract}
Introduction-The contribution of platelet activation to the pathogenesis of sickle cell disease (SCD) remains uncertain. We evaluated the safety and efficacy of eptifibatide, a synthetic peptide inhibitor of the aIIb $\beta 3$ receptor, in SCD patients during acute painful episodes.
\end{abstract}

\begin{abstract}
Materials and Methods-In this single site, double-blind, placebo-controlled trial, eligible patients with SCD admitted for acute painful episodes were randomized to receive eptifibatide or placebo at a ratio of 2:1.

Results-Thirteen patients (SS - 10, $\mathrm{S}^{0}-2$, SC - 1) were randomized to receive either eptifibatide ( $\mathrm{N}=9$; 6 females; median age - 25 years) or placebo $(\mathrm{N}=4 ; 3$ females; median age - 31 years). In the intent-to-treat analysis, there were no major bleeding episodes in either the eptifibatide or placebo arms (point estimate of difference: $0.00,95 \% \mathrm{CI} ;-0.604,0.372$ ). There was one minor bleeding episode in the eptifibatide arm (point estimate of difference for any bleeding: $0.11,95 \%$ CI: $-0.502,0.494)$. There was no significant difference in the proportion of patients with thrombocytopenia between the treatment groups (point estimate of difference: 0.11 , $95 \%$ CI: $-0.587,0.495)$. There were no differences in the median times to discharge, times to crisis resolution or the median total opioid use.
\end{abstract}

Conclusions-In this small study, eptifibatide appeared to be safe, but did not improve the times to crisis resolution or hospital discharge. Adequately powered studies are required to evaluate the safety and efficacy of eptifibatide in SCD. Clinicaltrials.gov Identifier:

NCT00834899.

() 2013 Elsevier Ltd. All rights reserved.

Corresponding Author: Kenneth I. Ataga, MBBS, Division of Hematology/Oncology, University of North Carolina at Chapel Hill, Physicians' Office Bldg., $3^{\text {rd }}$ Floor, CB\# 7305, 170 Manning Drive, Chapel Hill, NC 27599-7305, Tel: 919 843-7708, Fax: 919 966-6735, kataga@med.unc.edu.

* Current Address: Division of Hematology, The Ohio State University, Columbus;

**Vascular Biology Center, Georgia Regents University, Augusta, GA

DISCLOSURE OF CONFLICTS OF INTERESTS

Kenneth I. Ataga is a consultant to Pfizer and has served on scientific advisory boards for Adventrx, HemaQuest, Sangart and Selexys. Leslie V. Parise is a consultant for Biogen Idec and BD.

Publisher's Disclaimer: This is a PDF file of an unedited manuscript that has been accepted for publication. As a service to our customers we are providing this early version of the manuscript. The manuscript will undergo copyediting, typesetting, and review of the resulting proof before it is published in its final citable form. Please note that during the production process errors may be discovered which could affect the content, and all legal disclaimers that apply to the journal pertain. 


\section{Keywords}

Sickle cell disease; Eptifibatide; Platelet activation; acute painful episode; safety; Pain crisis; Inflammation

Sickle cell disease (SCD) is characterized by a "hypercoagulable state," with alterations in platelet function, coagulation activation and activation of fibrinolysis in the direction of a procoagulant phenotype (1). Patients with SCD exhibit increased platelet expression of CD62P (P-selectin), CD40 ligand (CD40L) and activated aIIbß3 receptors (2-4), as well as elevated plasma levels of the a-granule constituents, platelet factor 4 and $\beta$-thromboglobulin (5), in the non-crisis, "steady state," compared to healthy, control subjects. In addition, the level of the inflammatory mediator, $\mathrm{CD} 40 \mathrm{~L}$, is increased in the plasma and significantly reduced in the platelets of SCD patients compared to healthy individuals during the noncrisis, "steady state" (6). Multiple studies report further increases in markers of platelet activation during SCD-related acute pain episodes compared to periods without pain $(5,6)$. The frequency of pain episodes has been reported to correlate with enhanced platelet procoagulant activity measured during periods without pain (5). Furthermore, the plasma level of CD40L obtained during the non-crisis, "steady state" is significantly associated with the frequency of acute pain episodes in patients with "clinically severe" SCD genotypes (HbSS/HbSD/HbS $\beta^{0}$ thalassemia) (7).

CD40L, a type II transmembrane protein and a member of the tumor necrosis factor superfamily (8), is inducibly expressed on leukocyte subsets, smooth muscle, and epithelial cells, and mediates a broad variety of immune and inflammatory responses (9), both in its membrane-bound and soluble forms $(10,11)$. Upon activation, CD40L is exposed to the platelet surface and is released as a soluble fragment into the plasma (12). The integrin, aIIb $\beta 3$ is required for platelet activation and the release of CD40L (13). Our previous observation that the CD40:CD40L interaction increases the expression of tissue factor and intercellular adhesion molecule-1, as well as B-cell proliferation suggests that CD40L may contribute to the pathophysiology of vaso-occlusion in SCD (6).

Eptifibatide is a highly specific, reversible, synthetic peptide inhibitor of the $\alpha \mathrm{IIb} \beta 3$ receptor that acts at the final common step of the platelet aggregation pathway (14). Eptifibatide inhibits fibrinogen binding to ADP-activated platelets ex vivo (15); disperses platelet aggregates in vitro (16); inhibits soluble CD40 ligand and platelet-derived cytokine RANTES release ex vivo and in vitro $(17,18)$; inhibits IL-1 receptor antagonist levels ex vivo (19); inhibits $\alpha \mathrm{V} \beta 3$ integrin-mediated binding in human smooth muscle cells and endothelial cells at concentrations above those achieved therapeutically (20); and improves endothelium-dependent and nitric oxide-mediated vasodilation in patients with coronary artery disease (21). In an earlier pilot study in SCD patients during the non-crisis, "steady state," eptifibatide was well tolerated, and appeared to decrease the level of soluble CD40L (22).

To further define the contribution of platelet activation to the pathophysiology of vasoocclusion in SCD, we performed a randomized, placebo-controlled pilot study to evaluate the safety and efficacy of eptifibatide in patients with SCD during acute pain episodes.

\section{MATERIALS AND METHODS}

\section{Subjects}

The study population was comprised of male and female patients with SCD (HbSS, HbS $\beta^{0}$ thalassemia and $\mathrm{HbSC}$ ) between the ages of 18 and 55 years, with serum creatinine $\leq 1.2$ 
$\mathrm{mg} / \mathrm{dl}$, serum transaminase values $<3$ times upper limits of normal, platelet count $\geq$ $150 \times 10^{6} / \mathrm{mm}^{3}$, normal baseline coagulation profile (PT/INR, PTT), adequate intravenous access, and sudden onset of pain involving one or more sites that was typical of usual pain episodes, who were able to understand the requirements of the study and willing to give informed consent. Women of child-bearing age were practicing an adequate method of contraception (oral contraception, depo-provera, bilateral tubal ligation or barrier method).

Exclusion criteria included a baseline hemoglobin $<6.0 \mathrm{gm} / \mathrm{dl}$, a history of major bleeding (such as gastrointestinal or intracranial bleeding) or a bleeding diathesis, an ongoing episode of acute chest syndrome, a past history of clinically overt stroke, severe hypertension (systolic BP > $200 \mathrm{mmHg}$ and/or diastolic $\mathrm{BP}>110 \mathrm{mmHg}$ ), major surgery within the six weeks preceding enrollment, pregnancy or breastfeeding, on chronic anticoagulation or chronic antiplatelet (including NSAID) therapy, a history of metastatic cancer, on a chronic transfusion program or had received a blood transfusion in the prior 8 weeks, a positive urine toxicology screen for barbiturates, cocaine or amphetamines, a history of alcohol abuse or had received any investigational drugs within the past 4 weeks.

The Institutional Review Board of the University of North Carolina, Chapel Hill, approved the study protocol. Each subject gave written informed consent.

\section{Study Design}

This study was conducted as a single-center, phase II randomized, double-blind, placebocontrolled study to evaluate the safety of eptifibatide, in combination with "standard of care," for the treatment of patients during an acute pain episode. Patients admitted with uncomplicated acute pain episodes were treated with opioid analgesics, typically administered by patient controlled analgesia (PCA), "gentle" hydration and incentive spirometry. The two primary safety assessments were: a) an evaluation for major bleeding episodes (defined as any episode, such as gastrointestinal or intracranial bleed that typically leads to hospitalization or other prolonged bleeding requiring a blood transfusion); and b) decrease in platelet counts occurring anytime from randomization up to the final follow-up visit (day $28-35$ ). We also conducted an exploratory analysis designed to assess the efficacy of eptifibatide in this clinical setting by measuring its effect on: the duration of both acute pain episodes (time from randomization to termination of the pain episode) and hospitalization (period from randomization to the time an order for discharge from the hospital was written); pain intensity (assessed using visual analog scale [VAS]); total opioid analgesic consumption; and the development of acute chest syndrome.

The study consisted of a Screening/Baseline Phase, Treatment Phase, Post-Treatment Phase and Follow-up Phase. The Screening/Baseline Phase, conducted upon admission with an acute pain episode, included informed consent, a history and physical examination and clinical laboratory tests (complete blood count [CBC]; coagulation studies [PT/INR, PTT]; routine chemistries to assess liver and renal function; electrocardiogram; urinalysis; urine toxicologic screen; chest X-ray [CXR]; and serum pregnancy test [if female, and of childbearing capacity]). The Treatment Phase started at randomization and lasted until completion of the study drug infusion. The study drug infusion was initiated as soon as possible following presentation with an acute pain episode, and no longer than 24 hours following presentation to the hospital. The Post-Treatment Phase lasted for 7 days or until resolution of the crisis, whichever was shorter, but no less than 24 hours after discontinuation of the study drug infusion. Patients were not discharged home from the hospital until they had met the protocol-required "crisis" resolution criteria. The pain episode was considered terminated when the patient stated that the crisis was resolved (defined as being ready to go home on oral analgesics) or all of the following criteria were met: 1) pain relief (pain scores $\leq 40$ ) maintained for at least 2 consecutive readings obtained 
at least 4 hours apart; 2) no parenteral analgesics had been administered for at least 12 hours; and 3) ability to walk normally (unless he/she was unable to walk for some other reason prior to the crisis onset). Patients who were hospitalized for longer than 7 days after the end of the study drug infusion were eligible to be discharged without meeting the protocol definition of "crisis" resolution based on the clinical judgment of the treating physician. The Follow-up Phase included safety evaluations that were completed at 14 to 17 days and 28 to 35 days after discontinuation of the study drug infusion.

We aimed to enroll 30 participants, but the trial was terminated early because of slow accrual. Although the final study sample size did not provide the intended level of precision for estimating safety or treatment effects, we explored trends in the safety and efficacy of eptifibatide to provide therapeutic and pathophysiological insights and to guide the development of future studies.

\section{Treatment}

Eligible subjects were randomized at a ratio of 2:1 to receive either eptifibatide or placebo (using randomly permuted blocks with random block sizes of 3 and 6). Patients randomized to the eptifibatide arm received two $180 \mu \mathrm{g} / \mathrm{kg}$ boluses of eptifibatide 10 minutes apart, followed by a continuous infusion at $2 \mu \mathrm{g} / \mathrm{kg} / \mathrm{min}$ for 6 hours. Patients randomized to the placebo arm received a saline solution delivered at a volume and rate identical to that of the active drug.

\section{Statistical Analyses}

Differences between treatment groups in the proportion of participants with a major bleed, any bleed (major or minor bleeding episodes) and thrombocytopenia, respectively, were calculated. 95\% confidence intervals (CI) were obtained using the method of Newcombe (23) with continuity correction (24). For each patient, the largest decrease in platelet counts observed across all measurement time points since baseline was determined and the decreases in platelet counts were summarized graphically by treatment group. Using the Hodges-Lehmann estimation procedure, 95\% CIs were obtained for the location shift in decreases in platelet counts for the eptifibatide group versus the control group (25).

For the exploratory endpoint of duration of pain episode, Kaplan-Meier estimates of the survival distributions were plotted by treatment group and an exact log rank test was used to compare the two treatment groups. Patients whose crises had not yet resolved by day 7 (when study pain assessments ended) were censored. The distributions of time until discharge and total opioid analgesic use by treatment group were summarized and HodgesLehmann procedure was used to provide exact $95 \%$ CIs for the location shift between the treatment groups. Graphical methods were used to summarize changes in VAS pain scores over time by treatment group.

\section{RESULTS}

Thirteen patients (SS - 10, S $\beta^{0}-2, \mathrm{SC}-1$ ) were randomized to receive either eptifibatide ( $\mathrm{N}$ $=9 ; 6$ females; median age -25 years $)$ or placebo $(\mathrm{N}=4 ; 3$ females; median age -31 years $)$ between August, 2009 and March, 2012 before the termination of the study (Figure 1). One patient in the eptifibatide arm refused further participation in the study following completion of the study drug infusion after she was found to be difficult to arouse, with associated fever, hypoxia and tachycardia. A chest $\mathrm{x}$-ray showed no infiltrates and she improved following a decrease in her opioid analgesics. One patient randomized to the placebo arm was withdrawn early because she had a lower hemoglobin level than was permissible for the study. Due to the small number of enrolled subjects, these 2 patients were included in the 
intent-to-treat population. The baseline demographic and laboratory data of the study subjects are shown in Table 1.

In the intent-to-treat analysis, there were no major bleeding episodes in either the eptifibatide or placebo arms. The point estimate of difference in the proportion with major bleeds between eptifibatide and placebo was 0.00 (95\% confidence interval [CI]; -0.604 , 0.372). This means that we can rule out a $37.2 \%$ increased or greater risk with high confidence in the proportion of individuals who would be expected to have a major bleed if using eptifibatide compared with placebo. There was one minor bleeding episode (epistaxis) in a patient on the eptifibatide arm. The point estimate of the difference in the proportion with any bleeding (major or minor) between eptifibatide and placebo was 0.11 (95\% CI: $-0.502,0.494)$. This means that we can rule out a $49.4 \%$ increased or greater risk with high confidence in the proportion of individuals who would be expected to have any bleeding if using eptifibatide compared with placebo. There was a slight trend for the largest decrease in platelet count to be greater in the eptifibatide arm compared to the placebo arm, although the difference was not statistically significant. The observed median of the largest platelet count drop was $97.0 \times 10^{9} / \mathrm{L}$ for the eptifibatide arm and $-5.0 \times 10^{9} / \mathrm{L}$ for the placebo arm. The Hodges-Lehman estimate of the location shift between the eptifibatide and placebo arms was -82 (95\% CI: $-281,54$; midpoint -113.5$)$. There was no significant difference in the proportion of patients with thrombocytopenia between the treatment groups. The point estimate of the difference in the proportion with thrombocytopenia between eptifibatide and placebo was 0.11 (95\% CI: $-0.587,0.495)$. This means that we can rule out a $49.5 \%$ increased or greater with high confidence in the proportion of individuals who would be expected to have thrombocytopenia if using eptifibatide compared with placebo.

The median time to crisis resolution based on the survival distributions was 3.0 days for both treatment arms. The only two participants who completed 7 days of pain assessments without crisis resolution were both in the eptifibatide group. There was no evidence of a significant difference in time until crisis resolution between groups (exact log-rank test, pvalue $=0.50$ ). The median time to discharge was 3.0 days for patients in the eptifibatide arm as well as those in the placebo arm. The Hodges-Lehman estimate of the location shift between the eptifibatide and placebo arms was -0.1 days $(95 \%$ CI: $-32.1,1.26$; midpoint -15.4). No differences were observed in the pain intensity for patients in the eptifibatide arm compared with those in the placebo arm. The median total opioid use was 400.2 morphine equivalents (ME) for subjects in the eptifibatide arm and $1471 \mathrm{ME}$ for subjects in the placebo arm. The Hodges-Lehman estimate of location shift between the eptifibatide and placebo arms was -65.8 (95\% CI: $-2519,1700$; midpoint -409.6). Finally, one episode of acute chest syndrome occurred in each treatment arm.

Twelve serious adverse events were reported in seven patients. Each of these 12 events (five sickle cell pain episodes in four patients, bilateral shoulder pain in one patient, adenovirus respiratory infection in one patient, bacteremia in one patient, worsening anemia in one patient, hypoxemia in 1 patient and acute chest syndrome in 1 patient) were judged as unrelated to the study drug, and most were thought to be due to the underlying SCD. The most commonly reported treatment-emergent adverse events are listed in Table 2.

Eptifibatide appeared to be well tolerated and no important between-group differences were noted in the occurrence of treatment-emergent adverse events.

\section{DISCUSSION}

There are two general approaches to therapy for vaso-occlusive pain episodes in SCD: a) acute intervention - an attempt to terminate or to shorten the duration of a vaso-occlusive pain episode; and b) prevention - an approach designed to reduce the frequency of vaso- 
occlusive pain episodes. Despite an improved understanding of the pathophysiology of SCD, acute intervention for severe pain episodes in SCD patients remains inadequate, consisting mainly of supportive care with opioid analgesics, gentle hydration and oxygen therapy (usually in the setting of hypoxia). Several pharmacological agents have been evaluated as potential intervention strategies for shortening the duration or severity of acute pain episodes with mixed results (26-31). Most of these interventions have not produced any clinically meaningful reduction in the duration of acute pain episodes. While a randomized, double blind study of tinzaparin in 253 patients with HbSS showed that patients treated with tinzaparin had a significant reduction in the number of days with the most severe pain, overall duration of pain crisis and duration of hospitalization compared to placebo (30), this intervention is not widely used as treatment for acute pain episodes.

Although eptifibatide has been associated with a small risk of major bleeding especially at vascular access sites in patients undergoing percutaneous coronary intervention (32), bleeding was not a substantial problem in our patients. We found that eptifibatide was well tolerated, with no observed major bleeding episodes. One subject, in the eptifibatide arm, had a minor bleeding episode with mild epistaxis. Thrombocytopenia has been reported following treatment with eptifibatide (33-35). No patients developed thrombocytopenia following treatment in this study. Although, as observed in several other studies $(32,36,37)$, no significant differences were observed in the platelet counts in our study patients treated with eptifibatide versus placebo, there was a trend for the largest decrease in platelet count to be greater in the eptifibatide arm. In addition, despite reports of increased agonist-induced platelet activation, augmented platelet-neutrophil and platelet-monocyte aggregation in-vivo, and consequent activation of leukocytes following treatment with unfractionated heparin and eptifibatide (38) that raise concerns for worsening vaso-occlusion, patients treated with eptifibatide in our study did not appear to experience worsening vaso-occlusive complications compared to those treated with placebo. While the only two subjects who completed 7 days of pain assessments without crisis resolution were both in the eptifibatide group, we are unable to attribute causality of these prolonged pain episodes to eptifibatide.

The lack of significant differences in the median times to discharge as well as the time to crisis resolution in patients in the eptifibatide arm compared with patients in the placebo arm may be related to the lack of adequate power to detect differences in these endpoints. In addition, adequately powered studies are required to evaluate the effect of eptifibatide on the utility of opioid analgesics as well as other efficacy endpoints during acute pain episodes in SCD.

There are multiple studies of antiplatelet agents in $\operatorname{SCD}(22,39-44)$. While the reported effects of these agents on pain episodes are mixed, the largest study, a randomized, doubleblind, placebo-controlled study evaluating the effect of ticlopidine in $140 \mathrm{HbSS}$ patients reported a reduction in the frequency, duration, and severity of acute pain episodes following 6 months of therapy (39). In addition, a recent study of the third-generation platelet $\mathrm{P} 2 \mathrm{Y}_{12}$ ADP receptor antagonist, prasugrel, showed that it significantly decreased plasma levels of markers of platelet activation compared to placebo and appeared to decrease the mean pain rate, although this did not achieve statistical significance (45). All of these data suggest that in adequately powered studies, antiplatelet agents may be beneficial in the prevention and/or treatment of pain episodes in SCD.

In conclusion, infusion of eptifibatide for 6 hours during acute pain episodes in patients with SCD appears to be safe and well tolerated in this small study. Although there were no significant differences in the time to crisis resolution or the time to discharge, the study was underpowered to evaluate these efficacy endpoints. The data presented here suggest that antiplatelet therapy may constitute a safe therapeutic approach for SCD during acute pain 
episodes. Adequately powered studies of eptifibatide and other antiplatelet agents are warranted.

\section{Acknowledgments}

This work was supported by NIH grant R21HL091265. Support for this work was also provided by an award from the North Carolina State Sickle Cell Program.

The authors would like to acknowledge the efforts of the medical monitor, Raj Kasthuri, MD as well as the Clinical and Translational Research Center at UNC-Chapel Hill, which is funded by NIH grants RR00046 and UL1RR025747.

\section{Abbreviations}

$\begin{array}{ll}\text { SCD } & \text { sickle cell disease } \\ \text { CD40L } & \text { CD40 ligand } \\ \text { PCA } & \text { patient controlled analgesia } \\ \text { CI } & \text { confidence intervals }\end{array}$

\section{References}

1. Francis R Jr. Platelets, coagulation, and fibrinolysis in sickle cell disease: their possible role in vascular occlusion. Blood Coagul Fibrinolysis. 1991; 2(2):341-53. [PubMed: 1893065]

2. Inwald DP, Kirkham FJ, Peters MJ, Lane R, Wade A, Evans JP, et al. Platelet and leucocyte activation in childhood sickle cell disease: association with nocturnal hypoxaemia. $\mathrm{Br} \mathrm{J}$ Haematology. 2000; 111(2):474-81.

3. Villagra J, Shiva S, Hunter LA, Machado RF, Gladwin MT, Kato GJ. Platelet activation in patients with sickle disease, hemolysis-associated pulmonary hypertension, and nitric oxide scavenging by cell-free hemoglobin. Blood. 2007; 110(6):2166-72. [PubMed: 17536019]

4. Wun T, Paglieroni T, Tablin F, Welborn J, Nelson K, Cheung A. Platelet activation and plateleterythrocyte aggregates in patients with sickle cell anemia. J Lab Clin Med. 1997; 129(5):507-16. [PubMed: 9142047]

5. Tomer A, Harker LA, Kasey S, Eckman JR. Thrombogenesis in sickle cell disease. J Lab Clin Med. 2001; 137(6):398-407. [PubMed: 11385360]

6. Lee SP, Ataga KI, Orringer EP, Phillips DR, Parise LV. Biologically Active CD40 Ligand Is Elevated in Sickle Cell Anemia Potential Role for Platelet-Mediated Inflammation. Arterioscler Thromb Vasc Biol. 2006; 26(7):1626-31. [PubMed: 16601237]

7. Ataga KI, Brittain JE, Desai P, May R, Jones S, Delaney J, et al. Association of coagulation activation with clinical complications in sickle cell disease. PloS one. 2012; 7(1):e29786. [PubMed: 22253781]

8. Schonbeck U, Mach F, Libby P. CD154 (CD40 ligand). The international journal of biochemistry \& cell biology. 2000; 32(7):687-93. Epub 2000/06/17. [PubMed: 10856699]

9. Schonbeck U, Libby P. The CD40/CD154 receptor/ligand dyad. Cellular and molecular life sciences: CMLS. 2001; 58(1):4-43. Epub 2001/03/07. [PubMed: 11229815]

10. Van Kooten C, Banchereau J. CD40-CD40 ligand: a multifunctional receptor-ligand pair. Advances in immunology. 1996; 61:1-77. Epub 1996/01/01. [PubMed: 8834494]

11. van Kooten C, Banchereau J. CD40-CD40 ligand. Journal of leukocyte biology. 2000; 67(1):2-17. Epub 2000/01/27. [PubMed: 10647992]

12. Henn V, Slupsky JR, Grafe M, Anagnostopoulos I, Forster R, Muller-Berghaus G, et al. CD40 ligand on activated platelets triggers an inflammatory reaction of endothelial cells. Nature. 1998; 391(6667):591-4. Epub 1998/02/19. [PubMed: 9468137]

13. Furman MI, Krueger LA, Linden MD, Barnard MR, Frelinger AL 3rd, Michelson AD. Release of soluble CD40L from platelets is regulated by glycoprotein IIb/IIIa and actin polymerization. 
Journal of the American College of Cardiology. 2004; 43(12):2319-25. Epub 2004/06/15. [PubMed: 15193700]

14. Curran MP, Keating GM. Eptifibatide: a review of its use in patients with acute coronary syndromes and/or undergoing percutaneous coronary intervention. Drugs. 2005; 65(14):2009-35. Epub 2005/09/16. [PubMed: 16162023]

15. Holmes MB, Sobel BE, Schneider DJ. Variable responses to inhibition of fibrinogen binding induced by tirofiban and eptifibatide in blood from healthy subjects. The American journal of cardiology. 1999; 84(2):203-7. Epub 1999/07/30. [PubMed: 10426341]

16. Moser M, Bertram U, Peter K, Bode C, Ruef J. Abciximab, eptifibatide, and tirofiban exhibit dosedependent potencies to dissolve platelet aggregates. Journal of cardiovascular pharmacology. 2003; 41(4):586-92. Epub 2003/03/27. [PubMed: 12658060]

17. Nannizzi-Alaimo L, Alves VL, Phillips DR. Inhibitory effects of glycoprotein IIb/IIIa antagonists and aspirin on the release of soluble CD40 ligand during platelet stimulation. Circulation. 2003; 107(8):1123-8. Epub 2003/03/05. [PubMed: 12615789]

18. Welt FG, Rogers SD, Zhang X, Ehlers R, Chen Z, Nannizzi-Alaimo L, et al. GP IIb/IIIa inhibition with eptifibatide lowers levels of soluble CD40L and RANTES after percutaneous coronary intervention. Catheterization and cardiovascular interventions: official journal of the Society for Cardiac Angiography \& Interventions. 2004; 61(2):185-9. Epub 2004/02/03. [PubMed: 14755809]

19. Aggarwal A, Schneider DJ, Terrien EF, Terrien CM Jr, Sobel BE, Dauerman HL. Comparison of effects of abciximab versus eptifibatide on C-reactive protein, interleukin-6, and interleukin-1 receptor antagonist after coronary arterial stenting. The American journal of cardiology. 2003; 91(11):1346-9. Epub 2003/05/28. [PubMed: 12767431]

20. Lele M, Sajid M, Wajih N, Stouffer GA. Eptifibatide and 7E3, but not tirofiban, inhibit alpha(v)beta(3) integrin-mediated binding of smooth muscle cells to thrombospondin and prothrombin. Circulation. 2001; 104(5):582-7. Epub 2001/08/02. [PubMed: 11479257]

21. Heitzer T, Ollmann I, Koke K, Meinertz T, Munzel T. Platelet glycoprotein IIb/IIIa receptor blockade improves vascular nitric oxide bioavailability in patients with coronary artery disease. Circulation. 2003; 108(5):536-41. Epub 2003/07/23. [PubMed: 12874186]

22. Lee SP, Ataga KI, Zayed M, Manganello JM, Orringer EP, Phillips DR, et al. Phase I study of eptifibatide in patients with sickle cell anaemia. Br J Haematology. 2007; 139(4):612-20.

23. Newcombe RG. Interval estimation for the difference between independent proportions: comparison of eleven methods. Statistics in medicine. 1998; 17(8):873-90. [PubMed: 9595617]

24. Stokes M, Koch G. Up To Speed With Categorical Data Analysis. 2011

25. Hodges J Jr. Hodges-Lehmann Estimators. Encyclopedia of Statistical Sciences. 1983; 3:642-45.

26. Brousseau DC, Scott JP, Hillery CA, Panepinto JA. The effect of magnesium on length of stay for pediatric sickle cell pain crisis. Acad Emerg Med. 2008; 11(9):968-72. [PubMed: 15347549]

27. Gladwin MT, Kato GJ, Weiner D, Onyekwere OC, Dampier C, Hsu L, et al. Nitric Oxide for Inhalation in the Acute Treatment of Sickle Cell Pain Crisis A Randomized Controlled Trial. JAMA. 2011; 305(9):893-902. [PubMed: 21364138]

28. Griffin TC, McIntire D, Buchanan GR. High-dose intravenous methylprednisolone therapy for pain in children and adolescents with sickle cell disease. N Eng J Med. 1994; 330(11):733-7.

29. Orringer EP, Casella JF, Ataga KI, Koshy M, Adams-Graves P, Luchtman-Jones L, et al. Purified poloxamer 188 for treatment of acute vaso-occlusive crisis of sickle cell disease. JAMA. 2001; 286(17):2099-106. [PubMed: 11694150]

30. Qari MH, Aljaouni SK, Alardawi MS, Fatani H, Alsayes FM, Zografos P, et al. Reduction of painful vaso-occlusive crisis of sickle cell anaemia by tinzaparin in a double-blind randomized trial. Thromb Haemost. 2007; 98(2):392. [PubMed: 17721622]

31. Weiner DL, Hibberd PL, Betit P, Cooper AB, Botelho CA, Brugnara C. Preliminary assessment of inhaled nitric oxide for acute vaso-occlusive crisis in pediatric patients with sickle cell disease. JAMA. 2003; 289(9):1136-42. [PubMed: 12622584]

32. The ESPRIT Investigators. Novel dosing regimen of eptifibatide in planned coronary stent implantation (ESPRIT): a randomised, placebo-controlled trial. The Lancet. 2000; 356(9247): 2037-44. 
33. Attaya S, Kanthi Y, Aster R, McCrae K. Acute profound thrombocytopenia with second exposure to eptifibatide associated with a strong antibody reaction. Platelets. 2009; 20(1):64-7. [PubMed: 19172524]

34. Tahir M, Banday A, Karim S, Sullivan PR. Acute Profound Thrombocytopenia Following Eptifibatide Administration. South Med J. 2010; 103(6):596-7. [PubMed: 20710158]

35. Tempelhof MW, Benzuly KH, Fintel D, Krichavsky MZ. Eptifibatide-Induced Thrombocytopenia: with Thrombosis and Disseminated Intravascular Coagulation Immediately after Left Main Coronary Artery Percutaneous Coronary Angioplasty. Tex Heart Inst J. 2012; 39(1):86. [PubMed: 22412237]

36. The IMPACT-II Investigators. Randomised placebo-controlled trial of effect of eptifibatide on complications of percutaneous coronary intervention: IMPACT-II. The Lancet. 1997; 349(9063): $1422-8$.

37. The PURSUIT Investigators. Inhibition of Platelet Glycoprotein IIb/IIIa with Eptifibatide in Patients with Acute Coronary Syndromes. N Eng J Med. 1998; 339(7):436-43.

38. Keating FK, Dauerman HL, Whitaker DA, Sobel BE, Schneider DJ. Increased expression of platelet P-selectin and formation of platelet-leukocyte aggregates in blood from patients treated with unfractionated heparin plus eptifibatide compared with bivalirudin. Thromb Res. 2006; 118(3):361-9. [PubMed: 16139336]

39. Cabannes R, Lonsdorfer J, Castaigne J, Ondo A, Plassard A, Zohoun I. Clinical and biological double-blind-study of ticlopidine in preventive treatment of sickle-cell disease crises. Agents Actions Suppl. 1984; 15:199. [PubMed: 6385647]

40. Chaplin H Jr, Alkjaersig N, Fletcher A, Michael J, Joist J. Aspirin-dipyridamole prophylaxis of sickle cell disease pain crises. Thromb Haemost. 1980; 43(3):218. [PubMed: 7006142]

41. Greenberg J, Ohene-Frempong K, Halus J, Way C, Schwartz E. Trial of low doses of aspirin as prophylaxis insickle cell disease. J Pediatr. 1983; 102(5):781-4. [PubMed: 6842340]

42. Osamo N, Photiades D, Famodu A. Therapeutic effect of aspirin in sickle cell anaemia. Acta Haematol. 1981; 66(2):102-7. [PubMed: 6794308]

43. Semple M, Al-Hasani S, Kioy P, Savidge G. A double-blind trial of ticlopidine in sickle cell disease. Thromb Haemost. 1984; 51(3):303. [PubMed: 6388012]

44. Zago M, Costa F, Ismael S, Tone L, Bottura C. Treatment of sickle cell diseases with aspirin. Acta Haematol. 1984; 72(1):61-4. [PubMed: 6433636]

45. Wun T, Soulieres D, Frelinger A, Krishnamurti L, Novelli E, Kutlar A, et al. A double-blind, randomized, multicenter phase 2 study of prasugrel versus placebo in adult patients with sickle cell disease. Journal of Hematology \& Oncology. 2013; 6(1):17. [PubMed: 23414938] 


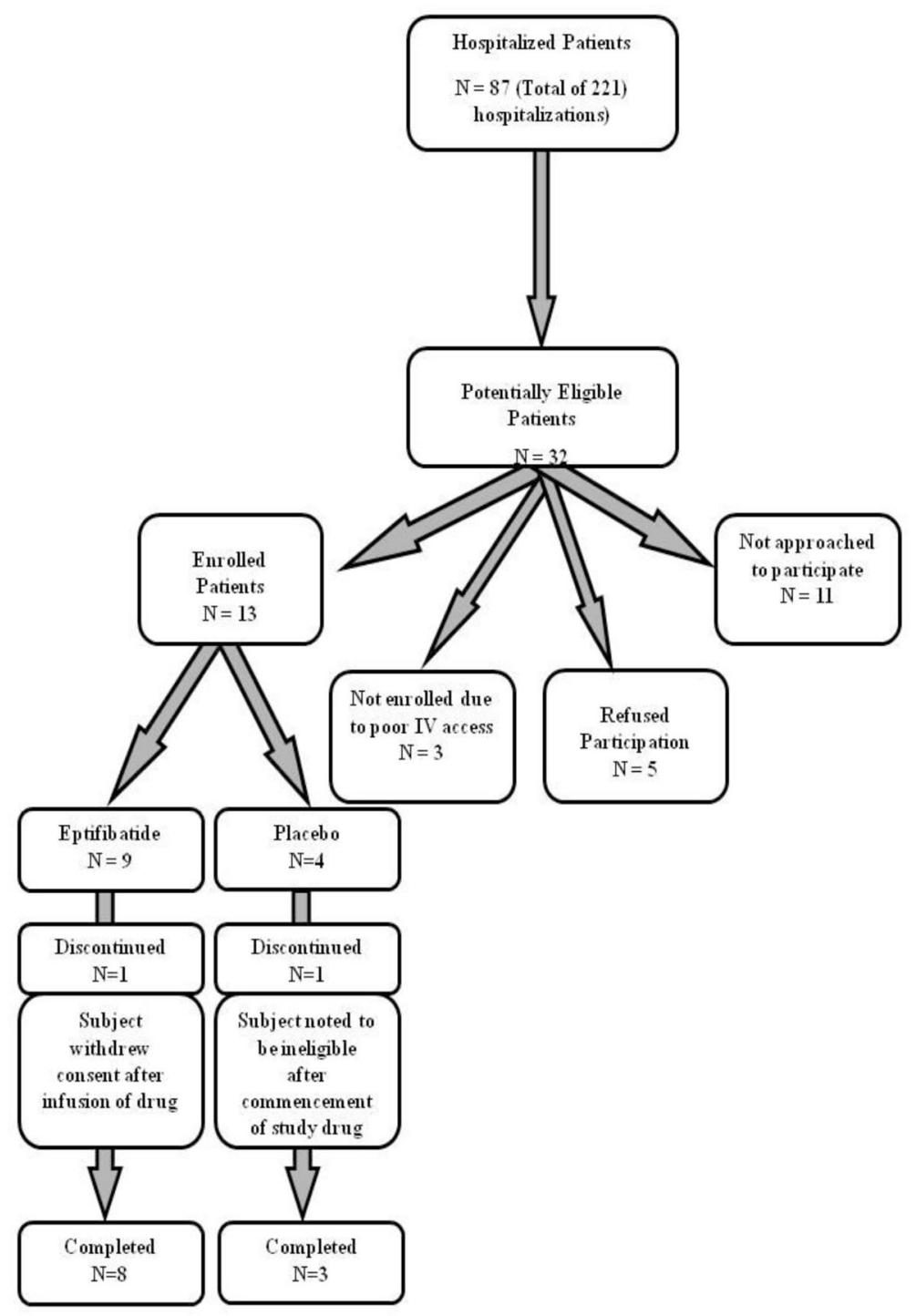

Figure 1.

Consort Diagram of Patient Enrollment 
Table 1

Baseline Demographics and laboratory Data of Study Patients

\begin{tabular}{|c|c|c|}
\hline Variable & Eptifibatide (N = 9) & Placebo $(\mathrm{N}=4)$ \\
\hline Age (years) [Range] & $25(22-48)$ & $31(24-50)$ \\
\hline \multicolumn{3}{|l|}{ Gender } \\
\hline (M) & $3(33)$ & $1(25)$ \\
\hline (F) & $6(67)$ & $3(75)$ \\
\hline \multicolumn{3}{|l|}{ Genotype } \\
\hline (SS) & $6(67)$ & $4(100)$ \\
\hline$\left(S \beta^{0}\right)$ & $2(22)$ & - \\
\hline (SC) & $1(11)$ & - \\
\hline Weight (Kg) & $72.1(56.7-100.1)$ & $59.0(56.0-62.4)$ \\
\hline White Blood Cell Count $\left(\times 10^{9} / \mathrm{L}\right)$ & $11.3(7.7-19.1)$ & $14.5(11.9-26.3)$ \\
\hline Absolute Neutrophil Count $\left(\times 10^{9} / \mathrm{L}\right)$ & $7.4(3.0-14.4)$ & $8.9(4.0-21.4)$ \\
\hline Hemoglobin (g/dL) & $8.1(5.9-10.6)$ & $7.5(5.5-9.3)$ \\
\hline Platelet Count $\left(\times 10^{9} / \mathrm{L}\right)$ & $521(96-829)$ & $397(317-519)$ \\
\hline Hemoglobin F (\%) & $9.35(0.3-29.3)$ & $8.6(7.3-17.5)$ \\
\hline Creatinine (mg/dL) & $0.7(0.38-1.09)$ & $0.53(0.45-0.80)$ \\
\hline Alanine Transaminase (U/L) & $29(7-64)$ & $42.5(31-65)$ \\
\hline Lactate Dehydrogenase (U/L) & $684(435-1235)$ & $981.5(719-1574)$ \\
\hline Total Bilirubin (mg/dL) & $1.9(0.7-2.8)$ & $2.45(1.6-10.7)$ \\
\hline
\end{tabular}

Median (Min-Max) provided for continuous variables. N (percent) for categorical variables 
Table 2

Frequency of Adverse Events * in patients on Eptifibatide and Placebo

\begin{tabular}{|l|l|l|}
\hline & \multicolumn{2}{|c|}{ Number (\%) of patients } \\
\hline Adverse Event & Eptifibatide (N = 9) & Placebo $(\mathbf{N}=\mathbf{4})$ \\
\hline Headache & $6(66.7)$ & $3(75)$ \\
\hline Sickle cell pain crisis & $3(33.3)$ & $1(25)$ \\
\hline Nausea & $3(33.3)$ & $1(25)$ \\
\hline Thrombocytosis & $2(22.2)$ & $0(0)$ \\
\hline Pruritus & $1(11.1)$ & $1(25)$ \\
\hline
\end{tabular}

* Patients were only counted once for each adverse event. Adverse events were included in the table if 2 or more patients reported an event in the two groups combined. 